\title{
RESEARCH
}

Open Access

\section{Correlation between urinary biomarker and organ failure in patients with sepsis and patients after esophagectomy: a prospective observational study}

Chieko Mitaka ${ }^{1 *}$ (D), Chika Ishibashi ${ }^{1}$, Izumi Kawagoe ${ }^{1}$, Takashi Hashimoto ${ }^{2}$, Makoto Takahashi ${ }^{3}$, Daizoh Satoh ${ }^{1}$ and Eiichi Inada'

\begin{abstract}
Background: Neutrophil gelatinase-associated lipocalin (NGAL) is a diagnostic marker for acute kidney injury (AKI). NGAL expression is highly induced not only in kidney injury but also in bacterial infection, inflammation, and cancer. The factors regulating NGAL expression are proinflammatory cytokines, and plasma NGAL levels have been increased in septic shock. However, there are no reports of urine neutrophil gelatinase-associated lipocalin (UNGAL) levels after open esophagectomy.

Methods: We prospectively enrolled critically ill patients, including patients with sepsis $(n=45)$ and patients who underwent open esophagectomy $(n=40)$. We compared vital signs, $\mathrm{PaO}_{2} / \mathrm{F}_{1} \mathrm{O}_{2}$, serum C-reactive protein (CRP) levels, acute physiology and chronic health evaluation (APACHE) II score, sequential organ failure assessment (SOFA) score, and UNGAL levels between the sepsis group and the esophagectomy group. Then, we investigated whether UNGAL is associated with the severity of illness and organ failure, and whether UNGAL is a reliable screening test for AKI.
\end{abstract}

Results: The median UNGAL levels, APACHE II score, SOFA score, and serum CRP levels were significantly $(p<0.001)$ higher in the sepsis group than in the esophagectomy group on ICU day 1. In the sepsis group, UNGAL levels were significantly $(p<0.05)$ correlated with APACHE II score and SOFA score on intensive care unit (ICU) day 1, 2, and 3. In the esophagectomy group, UNGAL levels were significantly $(p<0.05)$ correlated with SOFA score on ICU day 3 and 4 . In the sepsis group, 1 patient developed AKI stage 2 and 6 patients developed AKI stage 3. No patients developed AKI in the esophagectomy group. In a total of 85 patients of this study, 80 patients had an abnormal value of UNGAL and only 7 patients (8.7\%) of those 80 patients developed AKl.

Conclusions: UNGAL levels were correlated with the severity of illness and organ failure in critically ill patients. The value of UNGAL increases under the surgical and inflammatory responses, thereby losing a significance of a screening test of AKI in critically ill patients.

Keywords: Acute kidney injury, Biomarker, Esophageal cancer, Esophagectomy, NGAL (neutrophil gelatinaseassociated lipocalin), Organ dysfunction, Sepsis, Severity

\footnotetext{
*Correspondence: c-mitaka@juntendo.ac.jp

'Department of Anesthesiology and Pain Medicine, Juntendo University

Faculty of Medicine, 3-1-3 Hongo, Bunkyo-ku, Tokyo 113-8431, Japan

Full list of author information is available at the end of the article
}

(c) The Author(s). 2020 Open Access This article is distributed under the terms of the Creative Commons Attribution 4.0 International License (http://creativecommons.org/licenses/by/4.0/), which permits unrestricted use, distribution, and reproduction in any medium, provided you give appropriate credit to the original author(s) and the source, provide a link to the Creative Commons license, and indicate if changes were made. The Creative Commons Public Domain Dedication waiver (http://creativecommons.org/publicdomain/zero/1.0/) applies to the data made available in this article, unless otherwise stated. 


\section{Background}

Neutrophil gelatinase-associated lipocalin (NGAL), a 25 $\mathrm{kDa}$ protein of the lipocalin family, is a diagnostic marker for acute kidney injury (AKI) [1-3]. NGAL expression is highly induced not only in kidney injury [4, 5] but also bacterial infection, inflammation, and cancer [6-9]. The factors regulating NGAL expression are proinflammatory cytokines such as interleukins, tumor necrosis factor- $\alpha$ and interferons [7]. In fact, plasma NGAL levels have been increased in patients with septic shock [10-12].

On the other hand, open esophagectomy for esophageal cancer performed through a right-thoracotomy and laparotomy is a major invasive surgery [13, 14]. Surgical stress of radical esophagectomy induces the release of interleukin- 6 and interleukin- 8 and the overproduction of these cytokines induces systemic inflammatory response syndrome [15]. Therefore, open esophagectomy has a higher risk of intraoperative and postoperative complications. Although NGAL is highly expressed in esophageal squamous cell carcinoma $[8,9]$, there are no reports of uNGAL levels after open esophagectomy. In addition, NGAL is released from the lung, bronchi, and esophagus [7]. Therefore, we surmised that NGAL might be released from various organs such as the lung, bronchi, and esophagus during and after esophagectomy. The design of the present study required the selection of patients at risk for organ dysfunction. Therefore, we prospectively recruited critically ill patients with sepsis and patients after open esophagectomy with gastric reconstruction for esophageal cancer. Accordingly, we investigated in critically ill patients whether UNGAL is associated with the severity of illness and organ failure, and whether uNGAL is a reliable screening test for AKI.

\section{Methods}

\section{Study design and patients}

This CUBIC (correlation between urinary biomarker and organ failure in critically ill patients) study was a prospective observational study. The study protocol was approved by the Ethics Committee of Juntendo University Hospital. This study was performed in accordance with the ethical standards laid down in the 1964 Declaration of Helsinki and its later amendments. Informed written consent was obtained from patients or close relatives. This study was registered with the University Hospital Medical Information Network (UMIN 000024155). From January 2017 to April 2019, we prospectively enrolled 85 critically ill patients who were admitted to the intensive care unit (ICU) at the Juntendo University Hospital. Patients were followed up for 90 days after enrollment. The inclusion criteria were age $\geq 20$ years, critically ill patients with either sepsis or open esophagectomy with gastric reconstruction for esophageal cancer. Sepsis was defined as an increase in sequential organ failure assessment (SOFA) score [16] $\geq 2$ points caused by a dysregulated host response to infection according to definitions for Sepsis-3 [17]. The exclusion criteria were end-stage kidney disease and renal replacement therapy prior to intensive care unit (ICU) admission or kidney transplant. End-stage kidney disease is defined by a need for dialysis longer than 3 months [18].

\section{Data collection}

Demographic data for each participant were collected, including age, gender, and underlying diseases. The vital signs and arterial blood gas of each patient were measured and recorded. Routine blood tests including Creactive protein (CRP) level were conducted in the central laboratory of the hospital, and the results of the tests were recorded. uNGAL and urine creatinine levels were measured on ICU day 1, 2, 3, and 4. Spot urine was taken at admission to the ICU on day 1 and at 9:00 am on ICU day 2, 3, and 4. The definition of AKI was based on the Kidney Disease: Improving Global Outcomes (KDIGO) criteria: an increase in serum creatinine of at least $0.3 \mathrm{mg} / \mathrm{dL}$ from the baseline level within $48 \mathrm{~h}$ (AKI stage 1), serum creatinine 2.0-2.9 times baseline (AKI stage 2) and serum creatinine 3.0 times baseline or increase in serum creatinine $\geq 4.0 \mathrm{mg} / \mathrm{dL}$ (AKI stage 3) [19]. Acute physiology and chronic health evaluation (APACHE) II score [20] and SOFA score [16] were calculated.

Urine samples for uNGAL measurement were centrifuged at $1500 \mathrm{~g}$ for $10 \mathrm{~min}$ and the supernatants were stored at $-80^{\circ} \mathrm{C}$. uNGAL was measured by a chemiluminescent microparticle immunoassay using the ARCHITECT analyzer i2000 SR (Abbott Japan Co., Ltd., Tokyo, Japan). uNGAL was expressed as ng/mg creatinine to standardize and correct for changes in urine concentration. The upper limit level of uNGAL in a healthy subject was $30.5 \mathrm{ng} / \mathrm{mL}$ or $21.7 \mathrm{ng} / \mathrm{mg}$ creatinine.

In the sepsis group, crystalloid solution $(30 \mathrm{~mL} / \mathrm{kg}$ or more) was administered as initial fluid resuscitation at the early phase of sepsis, and 5\% albumin was administered in patients with hypoalbuminemia. Noradrenalin and vasopressin were administered to maintain mean arterial pressure more than $65 \mathrm{mmHg}$. Dobutamine was administered in patients with cardiac dysfunction. In the esophagectomy group, fluid infusion was controlled by hemodynamic monitoring and gradually reduced from ICU day 3. Mechanical ventilation was used in patients with respiratory failure in both groups.

We investigated the relationships between uNGAL levels and the severity of illness, organ failure, and inflammation in critically ill patients. In addition, we calculated the sensitivity and specificity of uNGAL for diagnosing AKI in a total of 85 patients. 


\section{Statistical analysis}

Quantitative data are expressed as the median and interquartile range (IQR). The intergroup differences were compared using the Mann-Whitney $U$ test. Categorical data are expressed as absolute values and percentages, and were analyzed using the chi-square test. The association of uNGAL levels with APACHE II score, SOFA score, and CRP levels were evaluated by Spearman's rank correlation test. $P<0.05$ was considered statistically significant.

\section{Results}

\section{Patient characteristics}

Critically ill patients included patients with sepsis $(n=$ $45)$ and patients after open esophagectomy with gastric reconstruction for esophageal cancer $(n=40)$. Sources of sepsis were intra-abdominal $(n=31)$, urinary tract $(n=$ $8)$, bloodstream $(n=2)$, and immunosuppression $(n=4)$ in patients with sepsis.

\section{Comparison of various parameters between the sepsis group and the esophagectomy group}

A comparison of various parameters between the sepsis group and the esophagectomy group on ICU day 1, 2, 3, and 4 are shown in Table 1 . Although there was no significant difference in age between the two groups, the male ratio was significantly $(p=0.0078)$ lower in the sepsis group than in the esophagectomy group. The median body temperature was significantly $(p=0.0092)$ lower in the sepsis group than in the esophagectomy group on ICU day1. However, the median body temperature was significantly $(p=0.0381)$ higher in the sepsis group than in the esophagectomy group on ICU day 4 . The median mean arterial pressure was significantly $(p=0.0047)$ lower in the sepsis group than in the esophagectomy group on ICU day 1 . The median $\mathrm{PaO}_{2} / \mathrm{F}_{\mathrm{I}} \mathrm{O}_{2}$ ratio was significantly $(p<0.05)$ higher in the sepsis group than in the esophagectomy group on ICU day $1,2,3$, and 4 . On the other hand, the median serum creatinine level was significantly $(p=0.0006)$ higher in the sepsis group than in the esophagectomy group on ICU day 1 . The median fluid infusion was significantly $(p=0.0204)$ higher in the sepsis group than in the esophagectomy group on ICU day 1 . The median uNGAL levels were significantly $(p<$ 0.001 ) higher in the sepsis group than in the esophagectomy group on ICU day 1, 2, 3 and 4. The median APACHE II score and median CRP level were significantly $(p<0.001)$ higher in the sepsis group than in the esophagectomy group on ICU day 1 . The median SOFA score was significantly $(p<0.05)$ higher in the sepsis group than in the esophagectomy on ICU day 1 and 2.

In the sepsis group, a combination of noradrenalin and vasopressin were administered in 6 patients and noradrenalin was administered in 18 patients, and dobutamine was administered in 3 patients. In the sepsis group, 7 patients underwent mechanical ventilation and the median duration of mechanical ventilation was 7 [IQR 4-17] days. In the esophagectomy group, 2 patients underwent mechanical ventilation and the duration of mechanical ventilation was 115 days and 18 days, respectively.

\section{Relationships between UNGAL and APACHE II score, SOFA score, and CRP}

UNGAL levels were significantly correlated with APACHE II score in the sepsis group $\left(r_{\mathrm{s}}=0.418, p<0.01\right.$, Fig. 1A), but uNGAL levels were not significantly correlated with APACHE II score in the esophagectomy group $\left(r_{\mathrm{s}}=0.011\right.$, Fig. $\left.1 \mathrm{~B}\right)$. In the sepsis group, uNGAL levels were significantly correlated with SOFA score on ICU day $1\left(r_{\mathrm{s}}=0.451, p<0.01\right.$, Fig. $\left.2 \mathrm{~A}\right)$, day $2\left(r_{\mathrm{s}}=0.531\right.$, $p<0.01$, Fig. 2B), day $3\left(r_{\mathrm{s}}=0.415, p<0.05\right.$, Fig. $\left.2 \mathrm{C}\right)$, but not on day $4\left(r_{\mathrm{s}}=0.312\right.$, Fig. $\left.2 \mathrm{D}\right)$. In the esophagectomy group, UNGAL levels were not significantly correlated with SOFA score on ICU day $1\left(r_{\mathrm{s}}=0.114\right.$, Fig. 3A) and day $2\left(r_{\mathrm{s}}=0.243\right.$, Fig. $\left.3 \mathrm{~B}\right)$, but they were significantly correlated with SOFA score on day $3\left(r_{\mathrm{s}}=0.323, p<\right.$ 0.05 , Fig. 3C) and day $4\left(r_{\mathrm{s}}=0.560, p<0.01\right.$, Fig. 3D). In the sepsis group, UNGAL levels were not significantly correlated with serum CRP levels on ICU day $1\left(r_{\mathrm{s}}=\right.$ $0.114)$, day $2\left(r_{\mathrm{s}}=0.077\right)$, and day $3\left(r_{\mathrm{s}}=0.262\right)$. In the esophagectomy group, uNGAL levels were not significantly correlated with serum CRP levels on ICU day 1 $\left(r_{\mathrm{s}}=0.008\right)$, day $2\left(r_{\mathrm{s}}=0.114\right)$, and day $3\left(r_{\mathrm{s}}=0.05\right)$.

\section{Relationship between UNGAL and AKI}

uNGAL levels were $>21.7 \mathrm{ng} / \mathrm{mg}$ creatinine (above normal range) in all septic patients. The details of uNGAL level in septic patients were $>21.7$ to $<50 \mathrm{ng} / \mathrm{mg}$ creatinine $(n=2), 50$ to $<150 \mathrm{ng} / \mathrm{mg}$ creatinine $(n=11), 15$ to $<1000 \mathrm{ng} / \mathrm{mg}$ creatinine $(n=17)$, and $>1000 \mathrm{ng} / \mathrm{mg}$ creatinine $(n=15)$. In the sepsis group, one patient developed AKI stage 2 and 6 patients developed AKI stage 3, who underwent continuous renal replacement therapy. The median uNGAL level in patients with AKI stage 3 was 2582.6 [IQR $1780-4457.8$ ] ng/mg creatinine on ICU day 1. The median uNGAL level was 3520.2 [IQR 1980.7-5932.5] ng/mg creatinine in 7 septic patients with AKI on ICU day 1 . Among these patients, uNGAL levels were remarkably elevated in 1 patient with loops enteritis (18,473.5 $\mathrm{ng} / \mathrm{mg}$ creatinine) on ICU day 2 and 1 patient with obstructive jaundice due to cholangiocarcinoma $(10,069.1 \mathrm{ng} / \mathrm{mg}$ creatinine) (AKI stage 2 ) on ICU day 1 . On the other hand, the peak UNGAL levels of 8 patients with urinary tract infection were 5203.7, 354.7, 3979.9, 10011, 6799.4, 4457.8, 4268.9, and $8660 \mathrm{ng} / \mathrm{mg}$ creatinine. Only 1 of these patients developed AKI stage 3 whose uNGAL level was $4457.8 \mathrm{ng} / \mathrm{mg}$ creatinine and underwent continuous renal replacement therapy. In the 
Table 1 Comparison of various parameters between the sepsis group and the esophagectomy group

\begin{tabular}{|c|c|c|c|c|}
\hline & All $(n=85)$ & Sepsis group $(n=45)$ & Esophagectomy group $(n=40)$ & $P$ value \\
\hline Age, years & $67[59-75]$ & $70[56-76]$ & $66[62-72]$ & 0.9470 \\
\hline Male, $n(\%)$ & $51(60 \%)$ & $21(47 \%)$ & $30(75 \%)$ & 0.0078 \\
\hline \multicolumn{5}{|c|}{ Body Temperature $\left({ }^{\circ} \mathrm{C}\right)$} \\
\hline Day 1 & $37.1[36.7-37.9]$ & $36.9[36.5-37.5]$ & $37.4[36.9-38.1]$ & 0.0092 \\
\hline Day 2 & $37.2[36.8-37.7]$ & $37.1[36.7-37.6]$ & $37.3[36.9-37.8]$ & 0.0926 \\
\hline Day 3 & $37.3[36.9-37.8]$ & $37.3[36.8-37.8]$ & $37.3[37.1-37.8]$ & 0.5998 \\
\hline Day4 & $37.0[36.6-37.4]$ & $37.1[36.9-37.4]$ & $36.8[36.5-37.2]$ & 0.0381 \\
\hline \multicolumn{5}{|c|}{ MAP (mmHg) } \\
\hline Day 1 & $71[61-84]$ & $65[58-75]$ & 79 [68-93] & 0.0047 \\
\hline Day 2 & $76[68-86]$ & 76 [70-86] & 76 [68-88] & 0.8020 \\
\hline Day 3 & 88 [75-94] & 85 [74-94] & 89 [76-94] & 0.8903 \\
\hline Day 4 & 90 [74-99] & 89 [71-102] & 88 [77-95] & 0.8111 \\
\hline \multicolumn{5}{|c|}{ Heart rate (/min) } \\
\hline Day 1 & 93 [85-108] & 93 [83-112] & 94 [87-106] & 0.8395 \\
\hline Day 2 & 89 [78-99] & $86[74-100]$ & 90 [86-95] & 0.4170 \\
\hline Day 3 & 91 [77-103] & 89 [72-106] & 92 [87-101] & 0.4884 \\
\hline Day 4 & 89 [74-98] & 88 [74-101] & 86 [78-101] & 0.9632 \\
\hline \multicolumn{5}{|c|}{ Respiratory rate (/min) } \\
\hline Day 1 & $22[20-26]$ & $22[20-26]$ & $23[20-26]$ & 0.9368 \\
\hline Day 2 & 20 [18-24] & 20 [18-24] & 20 [20-23] & 0.5720 \\
\hline Day 3 & 20 [17-24] & 19 [16-24] & 21 [18-24] & 0.1031 \\
\hline Day 4 & 20 [18-23] & 21 [18-23] & 20 [19-23] & 0.6380 \\
\hline \multicolumn{5}{|l|}{$\mathrm{PaO}_{2} / \mathrm{F}_{1} \mathrm{O}_{2}$} \\
\hline Day 1 & 277 [214-348] & 298 [230-412] & 243 [203-287] & 0.0140 \\
\hline Day 2 & 288 [223-353] & $331[235-444]$ & 260 [212-308] & 0.0206 \\
\hline Day 3 & 258 [210-318] & 305 [229-346] & 231 [207-289] & 0.0101 \\
\hline Day 4 & 257 [210-315] & 320 [264-353] & 240 [187-269] & $<0.0001$ \\
\hline \multicolumn{5}{|l|}{ Fluid (mL/h) } \\
\hline Day 1 & 132 [110-180] & 165 [118-229] & 124 [108-151] & 0.0204 \\
\hline Day 2 & 125 [106-148] & 134 [103-167] & 120 [107-132] & 0.1036 \\
\hline Day 3 & 111 [100-132] & 110 [95-150] & 110 [100-125] & 0.7830 \\
\hline Day 4 & 98 [89-113] & 103 [89-132] & 96 [87-104] & 0.0736 \\
\hline \multicolumn{5}{|l|}{$\mathrm{s} C r(\mathrm{mg} / \mathrm{dL})$} \\
\hline Day 1 & 0.80 [0.59-1.16] & 1.11 [0.67-1.92] & $0.72[0.57-0.82]$ & 0.0006 \\
\hline Day 2 & 0.82 [0.59-1.08] & 0.9 [0.61-1.33] & 0.76 [0.59-0.90] & 0.0978 \\
\hline Day 3 & 0.72 [0.59-1.02] & $0.75[0.6-1.26]$ & 0.69 [0.53-0.95] & 0.2986 \\
\hline Day 4 & $0.63[0.44-0.86]$ & $0.70[0.5-1.23]$ & $0.61[0.44-0.76]$ & 0.1602 \\
\hline \multicolumn{5}{|c|}{$\operatorname{eGFR}\left(\mathrm{mL} / \mathrm{min} / 1.73 \mathrm{~m}^{2}\right)$} \\
\hline Day 1 & 72 [44-93] & $46[27-85]$ & 82 [71-97] & $<0.0001$ \\
\hline Day 2 & 66 [47-92] & 57 [37-85] & 75 [64-94] & 0.0137 \\
\hline Day 3 & 74 [54-93] & $69[38-87]$ & 85 [62-99] & 0.0501 \\
\hline Day 4 & $86[67-114]$ & 78 [39-98] & $98[74-118]$ & 0.0214 \\
\hline \multicolumn{5}{|c|}{ uNGAL (ng/mg creatinine) } \\
\hline Day 1 & $81.1[26.2-461]$ & 461.4 [179.5-1893.9] & 27.1 [16.0-64.9] & $<0.0001$ \\
\hline Day 2 & $66.4[21.3-311.2]$ & 310.8 [108.4-1559.0] & $20.6[11.9-37.7]$ & $<0.0001$ \\
\hline Day 3 & $52.4[26.0-198.1]$ & $211.5[93.4-889.9]$ & 29.4 [16.5-44.5] & $<0.0001$ \\
\hline Day 4 & $43.8[26.9-100.5]$ & 217.7 [39.4-1285.8] & $37.9[22.1-64.6]$ & 0.0002 \\
\hline
\end{tabular}

CRP $(\mathrm{mg} / \mathrm{dL})$ 
Table 1 Comparison of various parameters between the sepsis group and the esophagectomy group (Continued)

\begin{tabular}{lllll}
\hline & All $(n=85)$ & Sepsis group $(n=45)$ & Esophagectomy group $(n=40)$ & $P$ value \\
\hline Day 1 & $1.7[0.6-12.2]$ & $12.1[5.4-19.2]$ & $0.6[0.3-0.8]$ & $<0.0001$ \\
Day 2 & $12.0[8.6-19.6]$ & $19.0[10.5-23.7]$ & $9.7[8.3-12.0]$ & $<.0001$ \\
Day 3 & $18.5[12.6-23.8]$ & $18.2[12.5-25.9]$ & $18.8[14.1-23.6]$ & 0.9544 \\
Day 4 & $14.3[11.1-19.6]$ & $13.4[11.2-16.0]$ & $10[1-20.4]$ & 0.5600 \\
APACHE II score & $12[9-14]$ & $14[10-18]$ & & $<0.0001$ \\
SOFA score & & & $3[2-4.3]$ & $2[2-3]$ \\
Day 1 & $4[2-7]$ & $6[2-10]$ & $3[2-5.5]$ & 0.0006 \\
Day 2 & $3[2-5]$ & $4[2-6]$ & $3[2-4]$ & 0.0323 \\
Day 3 & $3[2-4]$ & $3.5[3-5.8]$ & $8[8-8]$ & 0.8503 \\
Day 4 & $3[2-5]$ & $4[2-5]$ & $6[3-10]$ & 0.5415 \\
ICU stay (days) & $8[5-8]$ & 0.0043 &
\end{tabular}

The qualitative data are shown as number (percentage) and the quantitative data are shown as medians [interquartile ranges]. APACHE II, acute physiology and chronic health evaluation II; CRP, C-reactive protein: eGFR, estimated glomerular filtration rate; ICU, intensive care unit; MAP, mean arterial pressure; SOFA, sequential organ failure assessment; $\mathrm{s} C r$, serum creatinine; uNGAL, urine neutrophil

gelatinase-associated lipocalin

$P$ value, sepsis vs. esophagectomy

esophagectomy group, uNGAL levels were $<21.7 \mathrm{ng} / \mathrm{mg}$ creatinine (within normal range) $(n=5), 21.7-<50 \mathrm{ng} /$ $\mathrm{mg}$ creatinine $(n=11), 50-<150 \mathrm{ng} / \mathrm{mg}$ creatinine $(n=$ $19)$, and $150-<1000 \mathrm{ng} / \mathrm{mg}$ creatinine $(\mathrm{n}=5)$. No patients after esophagectomy developed AKI.

In a total of 85 patients of this study, 80 patients had an abnormal value of uNGAL and only 7 patients (8.7\%)

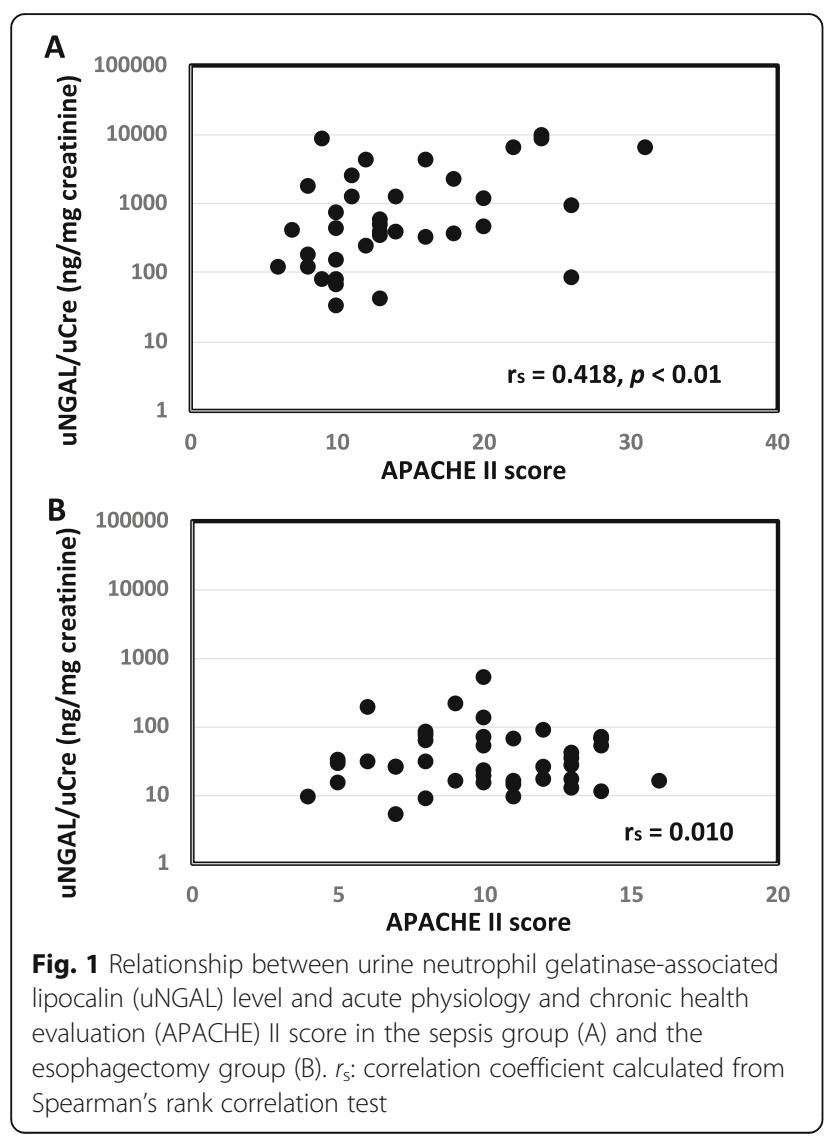

of those 80 patients developed AKI. At a cutoff value of $50 \mathrm{ng} / \mathrm{mg}$ creatinine, sensitivity and specificity of uNGAL for detecting AKI were 1.0 and 0.231 , respectively. At a cutoff value of $150 \mathrm{ng} / \mathrm{mg}$ creatinine, the sensitivity and specificity of UNGAL for detecting AKI were 1.0 and 0.615 , respectively.

uNGAL levels were not correlated with serum creatinine levels or eGFR in critically ill patients on each ICU day. Five patients with sepsis died within 90 days. The peak uNGAL levels of the 5 patients who died were $2889,66,1540,10011$, and $471 \mathrm{ng} / \mathrm{mg}$ creatinine.

\section{Discussion}

The major findings in the present study were that uNGAL levels were correlated with the severity of illness, organ failure, and inflammation in critically ill patients. In a total of 85 patients of this study, 80 patients had an abnormal value of uNGAL and only 7 patients (8.7\%) of those 80 patients developed AKI. The positive predictive value of AKI was 0.088 . Accordingly, a diagnostic ability of UNGAL for AKI can be masked under the surgical and inflammatory responses, thereby losing a significance of a screening test of AKI.

\section{Relationship between uNGAL and APACHE II score, SOFA score, and CRP}

The present study showed that UNGAL levels were significantly correlated with APACHE II score in the sepsis group. These findings indicate that uNGAL levels were correlated with the severity of illness in the sepsis group. In addition, the present study showed that uNGAL levels were significantly correlated with SOFA score in the sepsis group on ICU days 1,2, and 3. On the other hand, uNGAL levels were significantly correlated with SOFA score on ICU day 3 and 4 in the esophagectomy group. 

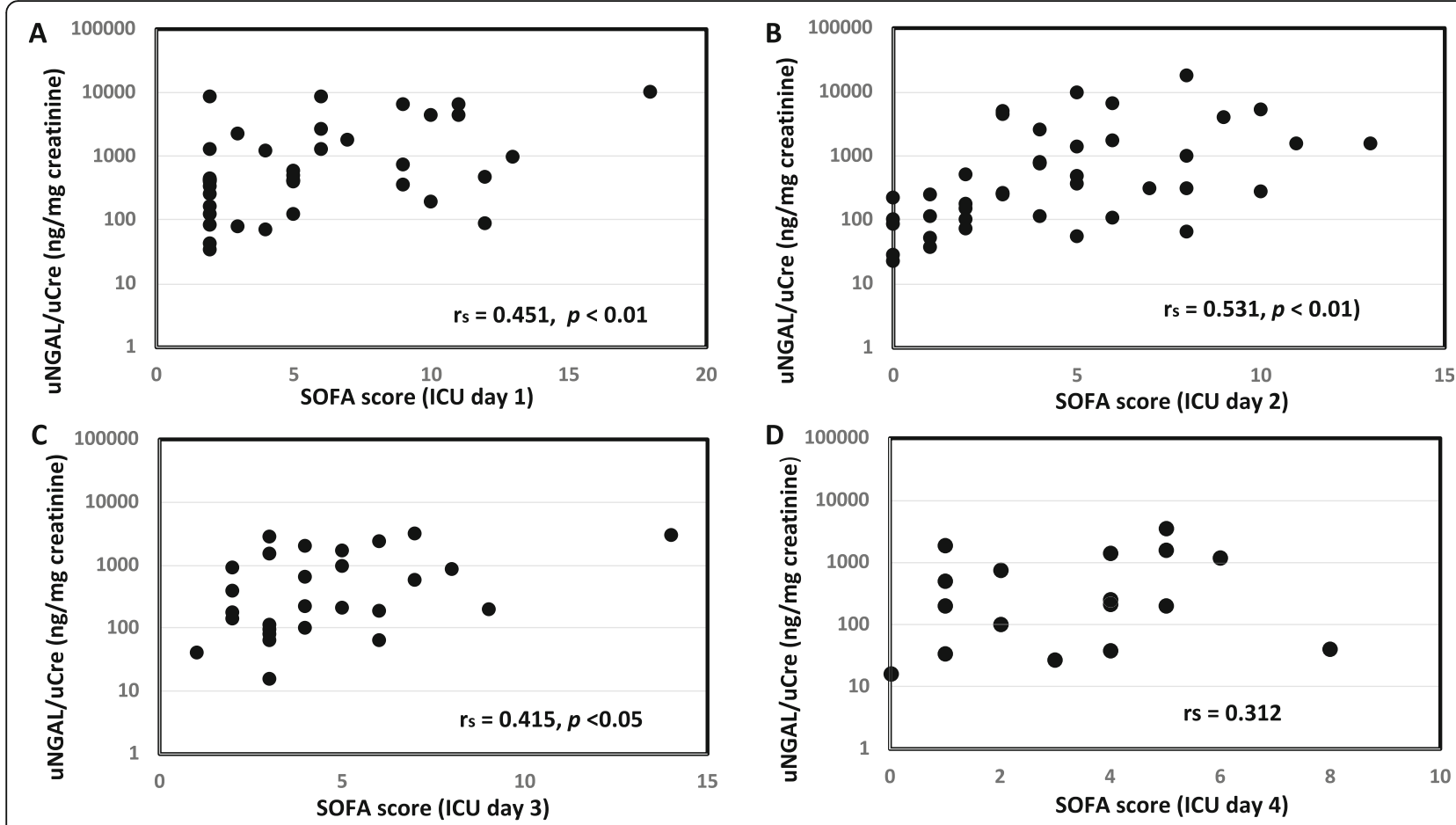

Fig. 2 Relationship between urine neutrophil gelatinase-associated lipocalin (UNGAL) level and sequential organ failure assessment (SOFA) score in the sepsis group on ICU day 1 (A), day 2 (B), day 3 (C), and day 4 (D)
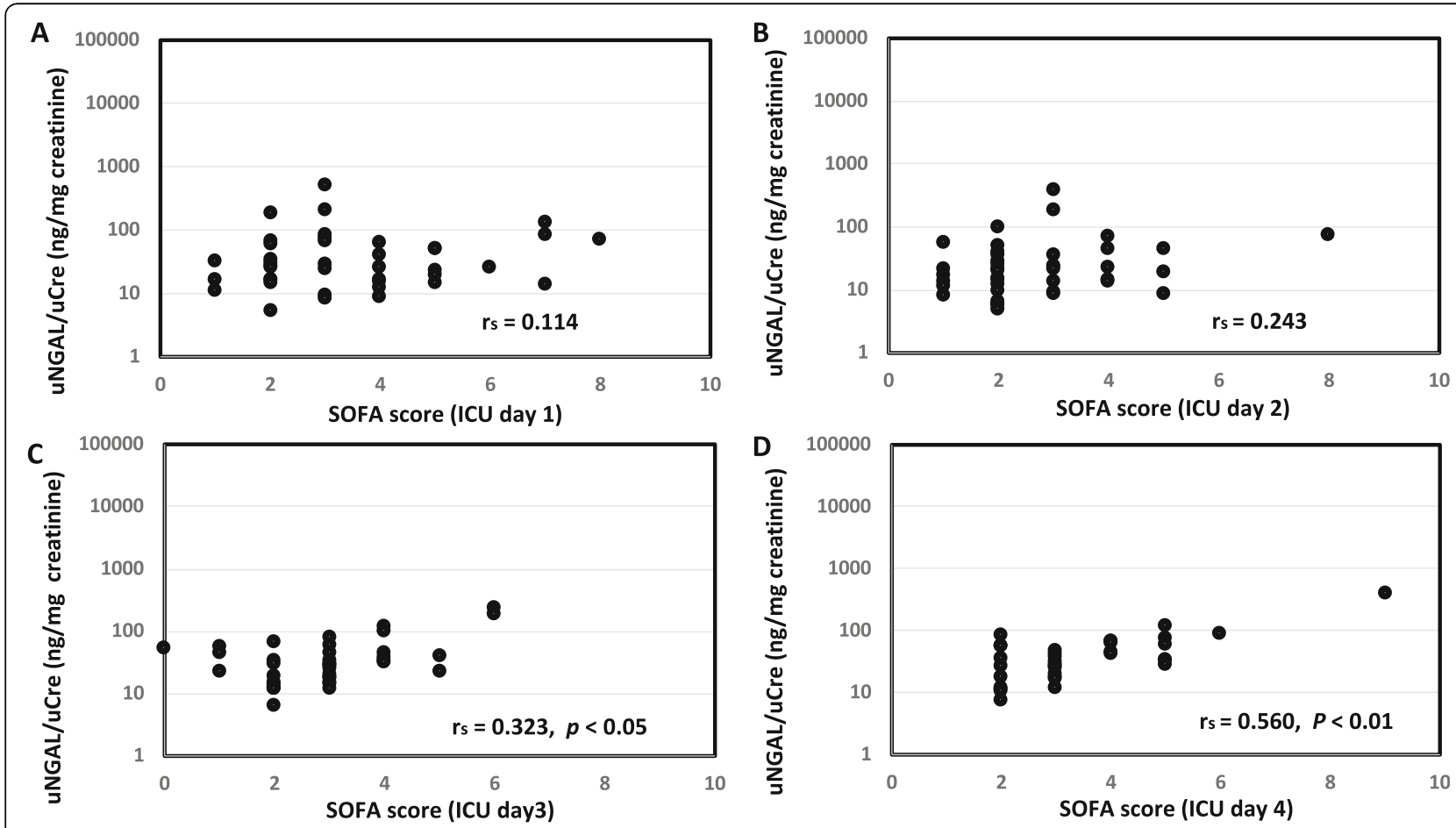

Fig. 3 Relationship between urine neutrophil gelatinase-associated lipocalin (UNGAL) level and sequential organ failure assessment (SOFA) score in the esophagectomy group on ICU day 1 (A), day 2 (B), day 3 (C), and day 4 (D). $r_{s}$ : correlation coefficient calculated from Spearman's rank correlation test 
These findings indicate that UNGAL levels were associated with organ failure, although the pattern of the sepsis group and the esophagectomy group was different. In the sepsis group, the relationships between UNGAL and APACHE II score, SOFA scores were found on ICU day 1,2 , and 3 , which were not found in the esophagectomy group. These results mean the increase in uNGAL levels was remarkable and occurred in the early phase of sepsis. Wang et al. [10] showed that high plasma NGAL levels were significantly associated with the APACHE II score, the SOFA score, and the CRP levels in severe sepsis and septic shock. Their study only measured plasma NGAL levels to assess the correlation with severity and organ failure. Although our study measured not plasma NGAL but uNGAL levels, relationships between uNGAL and APACHE II score and SOFA score are similar to their study. On the other hand, including patients after esophagectomy is different from their study. Shapiro NI, et al. [12] have reported in a multicenter observational study that a combination of plasma NGAL, interleukin-1 receptor antagonist, and protein $\mathrm{C}$ was predictive of organ dysfunction in 971 patients with suspected sepsis presenting to the emergency department. Because their study included not only plasma NGAL but also interleukin-1 receptor antagonist and protein $\mathrm{C}$ as a predictor of organ dysfunction, their study is different from our study.

\section{Relationship between UNGAL and AKI}

In the present study, uNGAL levels were 50 to $<150 \mathrm{ng} /$ mg creatinine $(n=30), 150$ to $<1000 \mathrm{ng} / \mathrm{mg}$ creatinine $(n=28)$, and $>1000 \mathrm{ng} / \mathrm{mg}$ creatinine $(n=15)$. de Geus et al. [21] have reported cardiac surgery-associated NGAL score as a potential tool to monitor acute tubular damage. This score shows that UNGAL level 50 to $<150$ $\mathrm{ng} / \mathrm{mL}$ is tubular damage possible, uNGAL level 150 to $<1000 \mathrm{ng} / \mathrm{mL}$ is tubular damage, and uNGAL level > $1000 \mathrm{ng} / \mathrm{mL}$ is severe tubular damage. The absolute cutoff level of $150 \mathrm{ng} / \mathrm{mL}$ for tubular damage was derived from identifying patients with acute tubular damage related to cardiac surgery or critical illness. Ueta K, et al. [22] demonstrated that the cutoff level of UNGAL for AKI prediction was $65.1 \mathrm{ng} / \mathrm{mg}$ creatinine in patients after endovascular stent graft repair of aortic aneurysm. Considering these findings, the present study showed that more than half of the patients had risk of tubular damage.

The median uNGAL level was significantly elevated to $3520.2 \mathrm{ng} / \mathrm{mg}$ creatinine in 7 septic patients with AKI on ICU day 1 , and 6 of these patients underwent continuous renal replacement therapy. Interestingly, 7 out of 8 patients with urinary tract infections, whose uNGAL levels were extremely elevated, did not develop AKI. Although Mori et al. [23] proposed that NGAL expression is a real-time indicator of active renal injury, we could not demonstrate an ability of UNGAL for predicting AKI in critically ill patients in the present study. Furthermore, although de Geus et al. [24] demonstrated that plasma NGAL and UNGAL levels at the time of ICU admission predict the development of severe AKI and the initiation of renal replacement therapy in critically ill patients, the results of the present study did not support the usefulness of uNGAL for predicting AKI.

Shavit et al. [25] evaluated serum NGAL and UNGAL as a predictor of AKI, morbidity and mortality in patients who underwent non-cardiac major surgery. No significant correlation was detected between serum NGAL or UNGAL and subsequent development of AKI. None of their patients developed severe AKI or required renal replacement therapy, which may reduce the predictive capacity of NGAL for AKI. However, serum NGAL or UNGAL was strongly correlated with postoperative infection and death. Their finding that none of their patients developed severe AKI or required renal replacement therapy is compatible with our patients after esophagectomy. In addition, their finding that surgical and inflammatory response and infection may reduce the predictive capacity of NGAL is very similar to our study.

\section{Study limitation}

There are several limitations in the present study. First, this study is a single-center study with a small number of critically ill patients. Second, we only measured uNGAL levels and did not measure plasma NGAL levels. Plasma NGAL is a marker of systemic inflammatory conditions, whereas UNGAL is specific for injury to the renal epithelium [26]. Therefore, uNGAL levels in patients with urinary tract infection were remarkably elevated in the present study. UNGAL levels and plasma NGAL levels may represent a more detailed situation in sepsis.

\section{Conclusions}

In conclusion, our results indicate that UNGAL levels were correlated with the severity of illness and organ failure in critically ill patients. A diagnostic ability of uNGAL for AKI can be masked under the surgical and inflammatory responses, thereby losing a significance of a screening test of AKI. The UNGAL level in patients with sepsis and patients after major surgery must be interpreted carefully by considering the inflammatory response and organ failure of the patients. Further largescale studies are needed to investigate the role of NGAL in sepsis.

\section{Abbreviations}

AKI: Acute kidney injury; APACHE: Acute physiology and chronic health evaluation; CRP: C-reactive protein; ICU: Intensive care unit; IQR: Interquartile 
range; KDIGO: Kidney Disease: Improving Outcomes; NGAL: Neutrophil gelatinase-associated lipocalin; sCr: Serum creatinine; SOFA: Sequential organ failure assessment; uCr: Urine creatinine; UMIN: University Hospital Medical Information; UNGAL: Urine neutrophil gelatinase-associated lipocalin

\section{Acknowledgements}

The authors acknowledge Abbott Japan Co., Ltd. (Tokyo, Japan) for assistance with UNGAL measurement.

\section{Authors' contributions}

$\mathrm{CM}$ designed the protocol and prepared the data listing. $\mathrm{CM}, \mathrm{Cl}$, and IK were involved in the acquisition of the data. TH and MT were involved in the surgery. CM and DS analyzed and interpreted the data and performed the statistical analysis. CM drafted the manuscript. El and DS were involved in the critical revision of the manuscript. All authors read and approved the final manuscript.

\section{Funding}

This study was supported by Abbott Japan Co., Ltd. (Tokyo, Japan). The funders had no role in the study design, the collection, analysis, and interpretation of the data, the preparation of the manuscript, or the decision to publish

\section{Availability of data and materials}

The datasets analyzed during the current study are available from the corresponding author on reasonable request.

\section{Ethics approval and consent to participate}

The study was approved by the Ethics Committee of Juntendo University Hospital. Informed written consent was obtained from patients or close relatives.

\section{Consent for publication}

Not applicable.

\section{Competing interests}

Chieko Mitaka received research funding and assistance with UNGAL measurement from Abbott Japan Co., Ltd.

\section{Author details}

'Department of Anesthesiology and Pain Medicine, Juntendo University Faculty of Medicine, 3-1-3 Hongo, Bunkyo-ku, Tokyo 113-8431, Japan. ${ }^{2}$ Department of Esophageal and Gastroenterological Surgery, Juntendo University Faculty of Medicine, 3-1-3 Hongo, Bunkyo-ku, Tokyo 113-8431, Japan. ${ }^{3}$ Department of Coloproctological Surgery, Juntendo University Faculty of Medicine, 3-1-3 Hongo, Bunkyo-ku, Tokyo 113-8431, Japan.

\section{Received: 5 October 2019 Accepted: 10 January 2020}

\section{Published online: 17 January 2020}

\section{References}

1. Mishra J, Dent C, Tarabishi R, Mitsnefes MM, Ma Q, Kelly C, et al. Neutrophi gelatinase-associated lipocalin (NGAL) as a biomarker for acute renal injury after cardiac surgery. Lancet. 2005;365:1231-8.

2. Haase M, Bellomo R, Devarajan P, Schlattmann P, Haase-Fielitz A, the NGAL meta-analysis investigator group. Accuracy of neutrophil gelatinase-associated lipocalin (NGAL) in diagnosis and prognosis in acute kidney injury: A systemic review and meta-analysis. Am J Kidney Dis. 2009;54:1012-24.

3. Nickolas TL, O'Rourke MJ, Yang J, Sise ME, Canetta PA, Barasch N, et al. Sensitivity and specificity of a single emergency department measurement of urinary neutrophil gelatinase-associated lipocalin for diagnosing acute kidney injury. Ann Intern Med. 2008;148:810-9.

4. Mori K, Lee T, Rapoport D, Drexler IR, Foster K, Yang J, et al. Endocytic delivery of lipocalin-siderophore-iron complex rescues the kidney from ischemia-reperfusion injury. J Clin Invest. 2005;115:610-21.

5. Kuwabara T, Mori K, Mukoyama M, Kasahara M, Yokoi H, Saito Y, et al. Urinary neutrophil gelatinse-associated lipocalin levels reflect damage to glomeruli, proximal tubles and distal nephrons. Kidney Int. 2009;75:285-94.

6. Flo TH, Smith KD, Sato S, Rodriguez DJ, Holmes MA, Strong RK, et al. Lipocalin 2 mediates an innate immune response to bacterial infection by sequestrating iron. Nature. 2004;432:917-21.
7. Chakraborty S, Kaur S, Guha S, Batra SK. The multifaceted roles of neutrophil gelatinase associated lipocalin (NGAL) in inflammation and cancer. Biochim Biophys Acta. 1826;2012:129-69.

8. Du ZP, Lv Z, Wu BL, Wu ZY, Shen JH, Wu JY, et al. Neutrophil gelatinaseassociated lipocalin and its receptor: independent prognostic factors of oesophageal squamous cell carcinoma. J Clin Pathol. 2011:64:69-74.

9. Wu BL, Li CQ, Du ZP, Zhou F, Xie JJ, Luo LW, et al. Functional analysis of the mRNA profile of neutrophil gelatinase -associated lipocalin overexpression in esophageal squamous cell carcinoma using multiple bioinformatics tools. Mol Med Rep. 2014;10:1800-12.

10. Wang B, Chen G, Zhang J, Xue J, Cao Y, Wu Y. Increased neutrophil gelatinaseassociated lipocalin is associated with mortality and multiple organ dysfunction syndrome in severe sepsis and septic shock. Shock. 2015:44:234-8.

11. Bagshaw SM, Bennett M, Haase M, Hasse-Fielitz A, Egi M, Morimatsu H, et al. Plasma and urine neutrophil gelatinase-associated lipocalin in septic versus non-septic acute kidney injury in critical illness. Intensive Care Med. 2010;36: 452-61.

12. Shapiro NI, Trzeciak S, Hollander JE, Birkhahn R, Otero R, Tiffany M, et al. A prospective, multicenter derivation of a biomarker panel to assess risk of organ dysfunction, shock, and death in emergency department patients with suspected sepsis. Crit Care Med. 2009;37:96-104.

13. Biere SS, van Berge Henegouwen MI, Maas KW, Bonavina L, Rosman C, Garcia JR, et al. Minimally invasive versus open oesophagectomy for patients with oesophageal cancer: a multicentre, open-label, randomised controlled trial. Lancet. 2012;379:1887-92.

14. Mariette C, Markar SR, Dabakuyo-Yonli TS, Meunier B, Pezet D, Collet D, et al. Hybrid minimally invasive esophagectomy for esophageal cancer. N Engl J Med. 2019;380:152-62.

15. Okumura A, Takeuchi H, Matsuda S, Ogura M, Miyasho T, Nakamura R, et al. Factors affecting cytokine change after esophagectomy for esophageal cancer. Ann Surg Oncol. 2015;22:3130-5.

16. Vincent JL, de Mendonça A, Cantraine F, Moreno R, Takala J, Suter PM, et al. Use of the SOFA score to assess the incidence of organ dysfunction/failure in intensive care units: results of a multicenter, prospective study. Working group on "sepsis-related problems" of the European Society of Intensive Care Medicine. Crit Care Med. 1998;26:1793-800

17. Singer MS, Deutschman CS, Seymour CW, Shankar-Hari M, Annane D, Bauer $M$, et al. The third international consensus definition for sepsis and septic shock (Sepsis-3). JAMA. 2016;315:801-10.

18. Bellomo R, Ronco C, Kellum JA, Mehta RL, Palevsky P, the ADQI workgroup. Acute renal failure - definition, outcome measures, animal models, fluid therapy and information technology need: the second international consensus conference of the acute dialysis quality initiative (ADQI) group. Crit Care. 2004:8:R204-12.

19. Kidney Disease: Improving Global Outcomes (KDIGO) Acute Kidney Injury Work Group. KDIGO clinical practice guideline for acute kidney injury. Section 2: AKI definition. Kidney Int Supple. 2012;2:19-36.

20. Knaus WA, Draper EA, Wagner DP, Zimmerman JE. APACHE II: a severity of disease classification system. Crit Care Med. 1985;13:818-29.

21. de Geus HR, Ronco C, Haase M, Jacob L, Lewington A, Vincent JL. The cardiac surgery-associated neutrophil gelatinase-associated lipoclin (CSANGAL) score: a potential tool to monitor acute tubular damage. J Thorac Cardiovasc Surg. 2016;151:1475-81.

22. Ueta K, Watanabe M, Iguchi N, Uchiyama A, Shirakawa Y, Kuratani T, et al. Early prediction of acute kidney injury biomarkers after endovascular stent graft repair of aortic aneurysm: a prospective observational study. J Intensive Care. 2014;2:45.

23. Mori K, Nakao K. Neutrophil gelatinase-associated lipocalin as the real-time indicator of active kidney damage. Kidney Int. 2007;71:967-70.

24. de Geus HR, Bakker J, Lesaffre EM, le Noble JL. Neutrophil gelatinaseassociated lipocalin at ICU admission predicts for acute kidney injury in adults patients. Am J Respir Crit Care Med. 2011;183:907-14.

25. Shavit L, Dolgoker I, Ivgi H, Assous M, Slotki I. Neutrophil gelatinase-associated lipocalin as a predictor of complication and mortality in patients undergoing non-cardiac major surgery. Kidney Blood Press Res. 2011;34:116-2.

26. Forster CS, Devarajan P. Neutrophil gelatinase-associated lipocalin: utility in urologic conditions. Pediatr Nephrol. 2017;32:377-81.

\section{Publisher's Note}

Springer Nature remains neutral with regard to jurisdictional claims in published maps and institutional affiliations. 